International Research Journal of Engineering, IT \& Scientific Research
Available online at https://sloap.org/journals/index.php/irjeis/
Vol. 7 No. 3, May 2021, pages: 76-86
ISSN: 2454-2261
https://doi.org/10.21744/irjeis.v7n3.1003

\title{
Advances in Applications of Non-Destructive Testing (NDT): A Review
}

Mridul Gupta ${ }^{\text {a }}$

Muhsin Ahmad Khan ${ }^{\text {b }}$

Article history:

Submitted: 27 January 2021

Revised: 18 February 2021

Accepted: 9 March 2021

\section{Keywords:}

acoustic emission; eddy current testing; manufacturing defects; non-destructive testing; ultrasonic testing;

\begin{abstract}
Manufacturing defects and discontinuities in a product are anomalies which can lead to severe damages which may sometimes involve loss of life. These defects must be examined and corrected before the product goes into service. There are two methods of testing a product for defects and discontinuities viz. Destructive Testing and Non-Destructive Testing. Destructive Testing entails subjecting the product to conditions that leads to failure of the product whereas Non-Destructive Testing (NDT) is the process of examining the products for defects in a way in which it retains its usefulness for future service. This paper discusses various methods involved in NDT such as Visual Testing, Magnetic Particle Inspection, Penetrant Testing, Ultrasonic Testing, Radiographic Testing, Acoustic Emission and Eddy Current Testing with a major focus on advances in the applications of NDT.
\end{abstract}

International research journal of engineering, IT \& scientific research (C) 2021. This is an open access article under the CC BY-NC-ND license (https://creativecommons.org/licenses/by-nc-nd/4.0/).

\section{Corresponding author:}

Gupta, M.

Department of Mechanical Engineering, Delhi Technological University, Bawana Rd, Shahbad Daulatpur Village, Rohini, Delhi, 110042

Email address: mridulgupta_2k18me131@dtu.ac.in

\footnotetext{
a Department of Mechanical Engineering, Delhi Technological University, Bawana Rd, Shahbad Daulatpur Village, Rohini, Delhi, 110042

b Department of Mechanical Engineering, Delhi Technological University, Bawana Rd, Shahbad Daulatpur Village, Rohini, Delhi, 110042 Email: muhsinahmadkhan_2k18me132@dtu.ac.in
} 


\section{Introduction}

One of the key objectives of the manufacturing industry is to ensure product quality i.e. to make sure the product is capable of performing its intended function for a long period of time. For a product to achieve this criteria, it is of utmost importance that the product be free of any defect and discontinuity. A defect is an imperfection in a product which can restrict its life by impeding the product's performance eventually causing it to fail, even during operation under ordinary conditions. A discontinuity is similar to a defect, the only difference being that a discontinuity can be rectified whereas a defect cannot. These anomalies can arise during manufacturing stages or even during the operation of the product. It is critical for these anomalies to be detected, studied and if possible be rectified. NonDestructive Testing or NDT consists of a range of techniques which enable the detection and evaluation of said anomalies in such a way that the product's condition is not exacerbated and can be rectified if possible. One of the greatest advantages of NDT is that they can be performed at all stages of product life, even during their operation. Not only does this provide an accurate idea about the location but also the properties (like dimensions, rate of propagation etc.) and the severity of the defect or discontinuity (Jolly et al., 2015; Gholizadeh, 2016).

The principles employed in various techniques of NDT are also employed in different fields. It is an implication that NDT is not only limited to manufacturing. For example, principles of NDT techniques are prevalent in medical diagnostics. X-Radiography used for detecting tumours, fractures etc and Remote Visual Testing used in procedures like endoscopy are some of the examples of NDT in the medical field. However, today major applications of NDT in manufacturing lie in automobiles, oil and gas, aerospace etc. There are other fields that use the principles of NDT like geological exploration, architecture etc. This paper aims at co-relating principles of various NDT techniques with advances in applications in fields which may or may not be manufacturing oriented.

\section{Literature Review}

According to P Cawley (2001) eddy current, ultrasonic, magnetic particle, radiography and penetrant testing are the 'big five' techniques that dominate the NDT market. Thus, research is being done continuously to reduce the preparation required, increase the speed of inspection and to inspect without shutting down the operation. How the process of using previous cases of data-interpretation to interpret the new data can be helpful in solving the issue of NDT data interpretation is shown by Jacek Jarmulak and others Jacek Jarmulak, Eugene J.H. Kerckhoffs, Peter Paul van't Veen (2001). The article shows how Case Based Reasoning (CBR) can be a successful alternative to expert systems and statistical classifiers.

Li Zhijun (2001) states that common defects and damages in composites can be effectively checked by the ultrasonic inspection method as compared to other methods of NDT. The author also introduces the development of studying and the applications of the ultrasonic method. According to G.S. Park and others G. S. Park, P. W. Jang, Y. W. Rho (2001), in a Magnetic Flux Leakage (MFL) type NDT system, the defect signals depend on the modification of the magnetic flux leakage in the area of defect. Thus, the authors describe a method to design a magnetic system which maximises the MFL in a NDT system.

P. Tschelisnig (2001) presents the principles of hyperbolic triangulation and the basis of propagation of waves. The author also explains the AE inspection systems by taking an example from TUV Vienna's 32 channel software and equipment. The results gained after the tests performed on the TUV Vienna are discussed in the integrity analysis and leakage tests. H. A. Crostack, W. Reimers ( 2001) state that the ability to measure internal and induced stresses or to differentiate between structures of materials can be provided by the Non-destructive testing. This inturn provides the data for the calculation of potential lifetime and reliability. They also state that the materials may be better understood by observing fast moving processes like crack propagation when they are under impact load.

Giovanni M. Carlomagnoet, Carosena Meola (2002) examines the application of infrared thermography in the field of architectural restoration by taking 3 samples made of a support of tuff, marble or brick and covering them with a layer of plaster. This layer of plaster is given inclusions to simulate cracks and detachments in frescoes. To detect the artificially induced flaws various techniques such as lateral heating thermography, pulse thermography, pulse phase thermography and modulated thermography are used. K. Bollas, D. Papasalouros, D. Kourousis \& A. Anastasopoulos (2011) discuss the monitoring of defects in the wheel sets of the trains using the Acoustic Emission (AE) monitoring method of NDT. The authors present the results of the AE measurements performed on the wheel sets of the trains with and without the defects, with varying speed and directions. The conclusions drwan show that

Gupta, M., \& Khan, M. A. (2021). Advances in applications of non-destructive testing (NDT): a review. International Research Journal of Engineering, IT \& Scientific Research, 7(3), 76-86. https://doi.org/10.21744/irjeis.v7n3.1003 
the $\mathrm{AE}$ monitoring method can be an efficient method for monitoring the wheel sets of the trains. Opportunities for the inspection of rock bolt in application such as reinforcement of coal mine roof, are limited to destructive techniques like pull-out test only. Thus, M.D. Beard and others Beard, M.J.S. Lowe (2003) try to develop a NDT technique for monitoring the condition of rock bolts.

Bruce W. Drinkwater, Paul D. Wilcox (2006) reviews the most relevant works on the use of ultrasonic arrays for non destructive evaluation applications in addition to which the author also discusses its future direction. The author also reviews the most relevant papers on the application of ultrasonic arrays in medical and sonar fields. On the other hand Malcolm K. Lim , Honggang Cao explain how one NDT technique is not sufficient for evaluation. Every technique has certain limitations which restrict their efficacy under different situations. The authors do so by differentiating the results between UT and ultra response method for evaluation of defects in a concrete structure.

A disadvantage of NDT is that most of the evaluations are heavily dependent upon the inspector's knowledge and experience. This is most relevant to magnetic particle inspection and penetrant testing, which also happen to be most used inspection techniques. Luk and Alan, H. S. Chan (2007) research on some of the human factors which may affect the accuracy of an evaluation and provide some suggestions in order to tackle these issues.

Gabriel Dan Taşcă, Gheorghe Amza explain how evaluation of complex parts can be done using NDT. Although $\mathrm{x}$-ray provides accurate data about a defect and is mostly preferred over other techniques, sometimes UT can provide better results. The authors also provide better insight as to how UT can provide more information other than just the nature of the defect or discontinuity but also how it occurred. Francesca Cau, Alessandra Fanni Augusto Montisci, Pietro Testoni, Mariangela Usai (2006) worked on detection of defects in pipes using UT. They evaluated the problem with the help of appropriate Artificial Neural Network models. Numerical Techniques like FEM have been used to evaluate problems in pipes by studying the echoes produced by ultrasonic waves.

Eddy Current testing has many variables that affect evaluations made by this method. Javier García-Martín, Jaime Gómez-Gil and Ernesto Vázquez-Sánchez (2011) provide a summary on these variables as well as recent advancements in this mode of NDT. The authors also explain how development in electronics and data evaluation systems have made Eddy current testing more effective. One of the advantages of NDT is that it can be done simultaneously while operating a machine. For example, Rainer Pohl, A Erhard, H.J Montag, H.-M Thomas, H Wüstenberg (2004) illustrated that Eddy current testing can be done on rail tracks simultaneously to trains travelling on them. The authors also emphasized other applications of NDT such as use of ultrasonic testing on railroad gauges and wheels. Umesh Singh, Mohan Singh and M. K. Singh (2012) illustrate the application of magnetic particle separation techniques used in the Indian mining industry. The authors provide an insight as to how this process has made inspection simple and cost effective as well as discuss the disadvantages of this technique.

Advancements in NDT have resulted in better evaluation of defects and discontinuities. D. Bracun, I. Polajnar, J. Diaci (2006) proposed a laser based technique for 3-D modelling of defects which use advanced algorithms to produce 3-D images with the help of electronic visual aids such as cameras. Most of the principles employed in NDT techniques are employed in other fields as well. In fact some of these techniques can be incorporated in improvising existing technology. One such example has been illustrated by Rodrigo Benenson, Stephane Petti, Thierry Fraichard, Michel Parent (2008) where they emphasize on the issues with self navigating cars. A combination of techniques such as ultrasonic waves and thermography can assess surrounding environments more accurately thus increasing reliability.

Another advantage of NDT is that it can be conducted at any stage of production. Lattice defects which are microscopic in nature, arise during material manufacture and affect overall physical integrity of any component. Gerd Dobmann, Iris Altpeter, Bernd Wolter (2008) show that NDT if incorporated at every stage of material production helps in making sure that these properties are uniform throughout.

\section{Results and Discussions}

\subsection{Visual Testing $(V T)$}

VT is the oldest mode of NDT. This method involves surface examination by visual aids, mainly the eye. The human eye is the most important visual aid that is required for conducting VT inspection. Light is an important requirement for conducting VT. The amount of light entering the eye determines the quality of the image. Several factors such as surface condition, brightness, temperature, size and shape of the object can affect the amount of light that is being reflected into the eye. Human factors such as physiological and environmental factors also affect the results of VT 
inspection. There are two types of VT methods, Direct VT (or DVT) and Remote VT (or RVT). Direct VT is carried out when the eye can be placed within 25 inches and at a minimum angle of 30 degrees to the surface of the specimen that is to be evaluated. Remote VT is done for sites which do not have proper accessibility and no illumination. In this mode, light is supplied by an external source via cable along with a camera which transmits images or a live feed on to a monitor .

Advantages- VT has major applications in building construction, aerospace, power plants etc. Some of the major advantages of VT are its simplicity, cost effectiveness and the ability to perform the test at any time. DisadvantagesHowever, its reliability is highly dependent upon a range of technological, physiological and environmental conditions as well as personnel knowledge. Disregarding any criteria of inspection can lead to inaccurate evaluations.

\subsection{Penetrant Testing (PT)}

PT is an application of capillary action. When a special liquid, called a penetrant, is applied on the surface of a component, usually by an aerosol, it fills any discontinuity that may be present by the virtue of capillary action. There are mainly two types of penetrants, fluorescent and visible dye penetrants. However due to better contrast ratio of fluorescent dyes, they are typically used for PT. The component to be inspected is immersed in the penetrant for some time and is then washed. It is then dried and observed under black light (fluorescent dyes). The set up for PT can be manual and or even automatic. However for simplicity in field inspection, dye penetrants (which do not require complicated setups) are used. PT done with dye requires an additional liquid called developer. Developer draws out the dye which may be entrapped in a discontinuity, making it visible. Factors such as wettability, capillary action, dry concentrate and viscosity determine the choice of penetrant to be used. Before any PT is done, there are certain prerequisites that should be noted: 1) temperature, if the surface is too cold a longer period of immersion is required and if it is too high the penetrant may evaporate, 2) environmental considerations which include flammability, fumes etc. 3) lighting and 4) surface condition such as coatings or rust should be addressed as it can affect the action of the penetrant.

Advantages- it is the most common mode of NDT because of its cost effectiveness, portability and versatility. Disadvantages- however like VT, PT is limited to surface defects. There are also many prerequisites and factors which affect the effectiveness of the test. A major concern with PT is that it is highly dependent upon the action of the penetrant, cleaning can remove the penetrant from discontinuities thereby evading the purpose of the test. This is known as overwashing.

\subsection{Magnetic Particle Inspection (MPI)}

MPI is a test based upon the behaviour of ferromagnetic materials when exposed to a magnetic field. Due to their high magnetic permeability, the domains align themselves in the direction of the applied magnetic force creating continuous lines. The underlying principle of MPI is studying the continuity of these lines of force, if the material is uniform then the lines are continuous. Whereas the lines distort in the case of a discontinuity because they tend to follow a path where they experience the least reluctance (ability of a domain to resist alignment in the direction of applied magnetic force). In order to do so these lines bend around the discontinuity creating a "distorted" field. Sometimes if discontinuities are large enough, these lines tend to exit the surface and form through air over the disconituity. This is known as leakage of magnetic fields. This leakage can be made visible by applying a ferromagnetic powder. The powder gets accumulated and a visible indication is observed. Usually iron filings are used but for improved visibility ferric oxide powder is used. The detection is however affected by physical factors such as thickness (thicker the material stronger the field required), material (different components affect permeability of the material) and internal stresses (effect on magnetic conductivity) of the component. Some other testing factors which include distancing between the magnetic poles and speed of detector also affect the results of MPI. Test results of MPI are instantaneous and easy to interpret.

Advantages-Virtually components of any size and shape can be tested by this technique and can be cheaper to perform than other methods. Like VT, it can be performed at any stage of manufacturing. Disadvantages- However, MPI is only restricted to testing of ferromagnetic materials and detection is limited to discontinuities on or near the surface. Sometimes discontinuities are hard to detect by this method due to the complex shape of a component. Sometimes due to formation of eddy currents, heating takes place which can cause damage to the component.

Gupta, M., \& Khan, M. A. (2021). Advances in applications of non-destructive testing (NDT): a review. International Research Journal of Engineering, IT \& Scientific Research, 7(3), 76-86. https://doi.org/10.21744/irjeis.v7n3.1003 


\subsection{Radiographic Testing $(R T)$}

RT is based upon the characteristics of radiation. Radiation is nothing but waves or particles emitted from a source passing through a medium. Radiography is the practice of capturing images by employing the characteristics of radiation. One of the key characteristics of radiation is that it can be absorbed by materials and the amount absorbed varies with thickness of the material. When radiation is made to pass through a component it is attenuated by the material. In regions of discontinuities, these rays experience lesser attenuation and travel faster in comparison to rays in uniform regions. The area of the film in the vicinity of the disconituity experiences more spot light and therefore a unique image is obtained making the discontinuity visible. There are mainly two types of radiations used in radiography, $\mathrm{x}$-radiation and gamma radiation. While gamma rays are produced from a radioactive source and $\mathrm{x}$-rays in a vacuum tube, characteristics of radiation apply to both.

Advantages- it is highly accurate and can be used on components of different shapes and sizes. Modern equipment has enabled the use of portable equipment which are just as effective as immobile ones. The major advantage lies in its ability to detect subsurface defects as opposed to the methods discussed previously. Disadvantages- subsurface defects can be observed only with proper orientation which can make the process time consuming and less reliable. Along with the health hazards, RT has material limitations. It can also be very expensive due to the high cost of machines and depletable sources of radiation. Gamma rays specifically are a major health hazard because of which x-rays are preferred over them.

\subsection{Ultrasonic Testing (UT)}

UT is based on the behaviour of sound waves. Sound is nothing but disturbance of particles in solid, liquid or gas. This disturbance is propagated at different frequencies in different media. In UT, a pulse generated by a piezoelectric material is propagated through a component. The frequency of this pulse is usually in the order of $10^{6} \mathrm{~Hz}$ to facilitate longer transmission distances. As long as the pulse travels through uniform regions, its properties will not be altered. Changes in properties of the pulse (like velocity) are indicative of a present discontinuity. The changes are detected by a transducer which converts sound energy into visual signals that can be displayed on LCD or CRT. The transducer can also detect sounds of inaudible frequencies, making UT accurate and reliable. The accuracy of UT depends upon variables like temperature which can affect the attenuation of waves and even the dimensions of the component. Surface condition is an important variable as tighter bound coatings facilitate better pulse transmission. Orientation of the discontinuity is however the most important factor in detection by UT.

Advantages- UT can also detect surface and subsurface defects. However unlike RT, the technology requires minimum consumables making it cheaper to operate. The equipment is also portable and easy to use. Another major advantage lies within its ability to detect smaller discontinuities. There are also techniques available to measure these defects as precisely as possible. Disadvantages- discontinuities of different orientations and of very small size may go undetected. Despite the visual aids and available techniques, improper evaluations can be made due to which UT requires highly skilled and experienced personnel.

\subsection{Eddy Current Testing (ECT)}

ECT is based on the fluctuation of the magnetic field induced due to eddy currents. When a metal is placed in a fluctuating magnetic field produced by alternating current in a loop, current is generated in the metal which is swirly in nature. These currents are called eddy currents. A typical ECT set up consists of two circuits, a primary and secondary circuit. The primary circuit is connected to an AC supply which sets up a primary fluctuating magnetic field which induces eddy currents in the test specimen. These eddy currents set up a secondary magnetic field which interferes with the primary magnetic field thereby affecting the current flowing through the coil. Therefore if eddy currents are altered then the current set up due to the secondary magnetic field is also affected thus changing the primary current. This change will produce a change in the impedance reading indicating a discontinuity. There are two types of ECT, pulsed ECT and Remote ECT. Pulsed ECT is used to detect defects in conductive materials and the latter is used for ECT in remote regions.

Advantages- equipment required for ECT is very portable and results are quick making it suitable for mass manufacture. The testing procedure is very safe and non-destructive. Disadvantages- ECT is limited to conducting materials. Evaluation of subsurface defects is difficult. In addition to this, eddy current theory is complicated. 


\subsection{Acoustic Emissions (AE)}

$\mathrm{AE}$ is based on the principle that when a material undergoes deformation, energy is released in the form of elastic waves of high frequency. These waves travel outwards to the surface. Deformations continue to release energy when they are subjected to further loading. These waves are called acoustic emissions. These acoustic emissions are then detected by sensors and the data is transmitted to a transducer which amplifies and converts the signals into interpretable data. One major difference between AE and other modes of NDT as discussed above is that in AE, disturbance is originating from the material and not from an external source. Normally, in other modes a disturbance is generated and transmitted through the specimen and the response is studied. AE can provide information about the origin of the discontinuity and propagation of the same. Attenuation and wave velocity are two important factors which affect the wave propagation process which ultimately influences detection.

Advantages- A major advantage of $\mathrm{AE}$ lies in the fact that it can be implemented at any stage, even during operation. It provides real time evaluation and has good economic viability. Disadvantages- different stresses produce different emissions and therefore different models of analysis are required. Another disadvantage is that observations can be influenced by unnecessary disturbances which can lead to inaccurate evaluations. Sometimes evaluation of a single defect can be disturbed by emissions of other discontinuities.

\section{Advances In Applications of NDT}

\subsection{Diagnostics and Protection of Cultural Heritage}

Requirement for the preservation of historic buildings involves a great knowledge of materials and structures, possible state of damage and its causes. In order to overcome the gap between the complexity of these structures and the initial low knowledge, experimental investigations which are on-site are recommended and required by Codes of Standards in many countries. The most arduous problems of unseen situations or detection of the mechanical behaviour of various structural elements like iron tie rods, timber roofs and floors, load bearing walls etc., can be solved using the Non- Destructive Testing techniques. In the instance of masonry the most often utilised NDTs are: thermovision, radar and sonic tests and as Minor Destructive techniques, the flat jack tests. Binda, L., Saisi, A., Tiraboschi, C. (2000) and Suprenant, B. \& Schuller, M. (1994) outline the main investigation techniques and their physical principles.

A significant information about the glass manufacturing technique employed can be extracted by using the NonDestructive Technique of Environmental Scanning Electron Microscopy and Fiber Optics Microscopy with an Energy Dispersive X-Ray analysis on glass fragments obtained from archaeological excavations E. Cheilakou, N. Liarokapi \& M. Koui (2011). A new Non-Destructive Technique which is Adaptable Neural Network Architecture was introduced by A.D. Doulamis \& T.A. Varvarigou (2011) in 2012 is capable of recognising the artistic styles incorporated in paintings. This technique can be very useful in preserving and restoring cultural paintings.

\subsection{On-site Measurement and Monitoring of Concrete by NDT}

Concrete is extensively used in various structures and defects in concrete structures can lead to severe damages and loss of life. These concrete structures often deteriorate unnoticed and in many cases the initial damage is not visible until there is a huge damage which is beyond repair. These problems occur due to the absence of quality check, no detection of fault during the initial construction stages, shrinkage cracking in the structures during the initial stages etc., all these problems and thus the structural failure can be prevented by using Non-Destructive Tests to check for defects during the initial stages only.

To improve the brittle behaviour, steel fibers are introduced into the concrete after which chemical coating of the fibers is done in order to attain maximum mechanical properties mainly toughness. For monitoring of structures, Acoustic Emission(AE) provides a way to identify between various fracture stages which are pre-peak and postpeak. The Acoustic Emission test also reveals the efficiency of chemical coating D.G. Aggelis, D.V. Soulioti, N.M. Barkoula, A.S. Paipetis \& T.E. Matikas (2011). NDT can act as a powerful tool providing valuable information about the current condition of a structure. Using NDT during the initial stages of building construction can help in identifying errors beforehand leading to easy repair as the error will be limited to a specific area, as proved by J.S.

Gupta, M., \& Khan, M. A. (2021). Advances in applications of non-destructive testing (NDT): a review. International Research Journal of Engineering, IT \& Scientific Research, 7(3), 76-86. https://doi.org/10.21744/irjeis.v7n3.1003 
Clausen, N. Zoidis \& A. Knudsen (2011) This helps in averting grave situations like loss of life and prevent them from happening in future. From a research done by E. Tatsis, N. Zoidis \& C. Vlachopoulos, T.E. Matikas and A. Gotzamanis, Ultrasonic method of NDT can also be used to estimate the condition of the structural elements and the extent of damages caused by a fire in a building E. Tatsis, N. Zoidis, C. Vlachopoulos, T.E. Matikas \& A. Gotzamanis (2011).

Shrinkage cracking is one of the major problems during the early stages in the concrete industry. It occurs primarily due to the usage of low quality aggregate which results in volumetric contraction of coarse aggregate. The detection of shrinkage cracking is very important and can be done by using the Acoustic Emission method of NDT which shows some promising results in identification of shrinkage cracking according to M. Ohtsu, T. Matsuo, S. Nozaki \& Y. Kawasaki (2011).

\subsection{Application of Ultrasonics}

As discussed above waves can be used to detect defects in a specimen be it a sound wave, a surface wave etc. They are made to propagate through the test specimen and the transmitted signals are monitored or interpreted. Surface waves as described by Rayleigh are the waves which move along the solid surface and their motion is restricted to a region close to the surface whose depth is akin to the wavelength. The surface waves have distinctive characteristics which helps in characterization and detection of surface-breaking defects in materials. Surface waves are sensitive to small defects because the energy of the surface waves is concentrated on the small layer in the neighborhood of the surface. Depending upon the defect size relative to the wavelength of the surface wave, they are diffracted, scattered and reflected by the surface defects. The surface waves have been used to characterize cracks in aluminum (Al) bars (Edwards et al. 2004, Palmer \& Dixon 2003, Edwards et al. 2006).

After a specific period of time fouling deposits start developing on the industrial pipes. These deposits are hard to prevent and pose a serious problem to the plant operators. There are a lot of varieties of fouling that may occur, entailing different chemical structures and elemental composition. The presence of fouling in the pipe results in corrosion, blockage, rupture and deformation which leads to substantial increase in operation cost and contamination of products. Pipe inspection can be done by involving ultrasonic guided waves Withers, 1994; Mc Cements, 1995; Hay \& Rose, 2003; Lohr \& Rose, 2003; da Silva et al, 2005; da Silva et al, 2007b). This technique which is capable of long range identification with great reliability, has been shown to identify not only fouling but also particular defects in pipes. As experimented by Ignacio Garcia de Carellan[35], due to the potential of conventional ultrasonic cleaning baths to eliminate hard deposits there is a possibility to break the bond between the fouling deposits and the steel pipe by using guided waves of sufficient magnitude.

\subsection{Application of Acoustic Emission (AE)}

As discussed above, every material produces high frequency sound known as the acoustic emission when they are stressed, deformed or are going through structural change such formation of crack. These emissions are inaudible to the human ear but can be detected by special devices which helps in knowing about the cracks that may lead to some serious damage in the future. Acoustic Emission monitoring is very useful in evaluating the quality of laser cutting. Laser cutting is a process of cutting a material using a laser. Quality of the laser cut is defined mainly by the state of the laser cut surface and the existence of the re-solidified material occurring as dross at the lower cut edge. Changes in the quality of beam, surface of materials and gas flow can lead to reduction in the quality of laser cut. While the laser cuts the material AE signals are emitted due to the interaction among the cutting gas, laser light and plate material. These AE signals can be captured during or immediately after the cutting process and the dross formation and the degradation of the laser cut surface can be detected thus helping in controlling the cutting process and ensuring high laser cut quality. T. Kek \& J. Grum (2011) proved by experimenting that this method of capturing AE signals to control the laser cutting process is applicable to unalloyed as well as alloyed steel(austenitic stainless steel) with different thickness.

Surface rail transportation is one of the most significant and important discoveries of modern technology. With time trains have been improving even if we exclude magnetic levitation technology, these improvements have increased the cruising quality as well as the speed. Still, due to the dynamic nature of loading and frequent working of the trains, deformations develop in the wheels and the axles. One of the major factors that leads to the deterioration of the wheel is the emergency braking. Emergency braking produces a lot of heat due to the friction which leads to small or large surfaces of the tyre to be flattened. These flattened surfaces can lead to misalignment, 
bad rolling quality, fatigue, lower speed etc. This defect can be detected by using AE monitoring as the wheels produce transient elastic waves to which AE monitoring is sensitive thus detecting the defects when the train passes. Wind turbine blades are one of the most vulnerable and exposed parts of the turbine. They are continuously in contact with the gushes of wind and sometimes exposed to severe weather conditions. This leads to deterioration of the blades. If the blades are deteriorated the turbine will not work thus, there is a need for monitoring these blades which can be done by using AE monitoring. N. Tsopelas, D. Kourousis, I. Ladis, A. Anastasopoulos, D.J. Lekou \& F. Mouzakis (2011) summarizes the first successful long-term AE monitoring of the full-scale in service Wind Turbine.

\subsection{Other Applications}

The ultrasonic method of NDT which is discussed above can be used in Quality Control of the Ground Improvement for setting up Crude oil Storage tanks. This method involves production of vertical impulses by the surface waves on the ground surface. The dispersive characteristic of the incoming wave after being reflected by the ground is calculated which gives the layer stiffness of the layered ground. This procedure permits measuring of shear modulus for profiles of the ground based on depth, with very small deformations before and after the improvement of the ground. The ratio of shear modulus before and after improvement represents an extent of ground improvement, which is then used as an estimate of successfulness for the conducted ground works. Using the ultrasonic method of NDT ensures the safety and stability of the oil storage tank M.S. Kovačević, A. Mirčeta \& D. Marčić (2011).

The Radiographic Inspection method of NDT that is discussed above can be used to scan the porous construction materials for the moisture content. If there is excessive moisture content in the construction material, it affects the physical properties of building structures. This leads to dampness and thus weakening the structure. The Radiographic Inspection method of NDT provides continuous and fast measurement and increased metering on a single sample without influence of human factor J. Skramlik, M. Novotny \& K. Suhajda (2011).

Aircrafts construction involves usage of carbon fiber laminates which are usually long fiber-enforced composite materials. Quality assurance activities are considered very important because separated fibers are regarded as weak areas. Thus, Structural Health Monitoring is becoming increasingly important nowadays. This structural health monitoring is done using Guided Waves i.e. Ultrasonic method of NDT and also by Acoustic Emission Monitoring technique of NDT.[40]

Ground transportation vehicles can also be monitored using Structural Health Monitoring. The wheel set of these vehicles produce sound signals which can be detected by using the Acoustic Emission Monitoring technique of NDT. If there is any damage in the wheel tread, such as pitting (production of cavities or holes), the sound signal produced changes and these changes in the signal can be detected by integrating AE monitoring system in the wheel set hollow shaft N. Meyendorf, B. Frankenstein \& L. Schubert (2011).

\section{Conclusion}

Principle of Non-Destructive testing is simple, to make sure a product conforms to its requirements physically and operationally by conducting a series of tests which do not tamper with the overall viability of the final product. One of the bigger disadvantages of NDT is that a single technique is not sufficient for total satisfaction. However, combining two or more techniques can ensure a greater sense of satisfaction. The underlying working principles of various NDT techniques have proved to be effective in every situation making NDT a relatively mature field. Scope of development in NDT lies in its application and technology. Development in material technology has broadened the field of application of NDT along with the development of electronics over the last few decades which has provided the field with enhanced and sophisticated equipment (with underlying working principles remaining unchanged) making NDT more reliable and cost effective. This paper described the various methods involved in NDT and identifies as well as compiles the advances in the applications of NDT, showing that the field is not only limited to the identification of an issue, but also its classification and rectification followed by preservation.

Gupta, M., \& Khan, M. A. (2021). Advances in applications of non-destructive testing (NDT): a review. International Research Journal of Engineering, IT \& Scientific Research, 7(3), 76-86. https://doi.org/10.21744/irjeis.v7n3.1003 
Conflict of interest statement

The authors declared that they have no competing interests.

Statement of authorship

The authors have a responsibility for the conception and design of the study. The authors have approved the final article.

Acknowledgments

We are grateful to two anonymous reviewers for their valuable comments on the earlier version of this paper. 


\section{References}

A.D. Doulamis \& T.A. Varvarigou (2011); Image analysis for artistic style identification: A powerful tool

Amenabar, I., Mendikute, A., López-Arraiza, A., Lizaranzu, M., \& Aurrekoetxea, J. (2011). Comparison and analysis of non-destructive testing techniques suitable for delamination inspection in wind turbine blades. Composites Part B: Engineering, 42(5), 1298-1305. https://doi.org/10.1016/j.compositesb.2011.01.025

B. L. Luk and Alan, H. S. Chan (2007); Human Factors and Ergonomics in Dye Penetrant and Magnetic Particles Nondestructive Inspection Methods.

Binda, L., Saisi, A., Tiraboschi, C. (2000); Investigation procedures for the diagnosis of historic masonries, Construction and Building Materials, Elsevier, 14(4), 199-233.

Bruce W. Drinkwater, Paul D. Wilcox (2006); Ultrasonic arrays for non-destructive evaluation: A review, NDT \& E International, 39(7), 525-541.

Construction and Building Materials, ISSN. 2003:0950-618

D. Bracun, I. Polajnar, J. Diaci (2006); Indentation shape parameters as indicators of spot weld quality; International Journal of Materials and Product Technology, 27(3/4), $247-257$.

D.G. Aggelis, D.V. Soulioti, N.M. Barkoula, A.S. Paipetis \& T.E. Matikas (2011); Influence of the fiber chemical coating on the fracture behavior of steel fiber concrete measured by acoustic emission, Proceedings of the fifth conference on Emerging Technologies in NDT, Ioannina, Greece, 111-116.

da Silva, J., Jaidilson J, Lima, Marcus N.A., da Rocha Neto \& Jose Sergio (2007b); Fouling detection using ultrasonic guided waves and parameter estimation, Third IFAC Symposium on System Structure and Control.

da Silva, J., Wanzeller, M.G., de Almeida Farias, P., da Rocha Neto \& Jose Sergio. (2005); Development of Circuits for Excitation and Reception in Ultrasonic Transducers for Generation of Guided Waves in Hollow Cylinders for Fouling Detection, Instrumentation and Measurement Technology Conference, 467-471.

E. Cheilakou, N. Liarokapi \& M. Koui (2011); NDT characterization of ancient glass objects from the Aegean with an approach of the manufacturing technique, Proceedings of the fifth conference on Emerging Technologies in NDT, Ioannina, Greece, 63-70.

E. Tatsis, N. Zoidis, C. Vlachopoulos, T.E. Matikas \& A. Gotzamanis (2011); Visual inspection and evaluation using NDT testing methods of industrial building after fire, Proceedings of the fifth conference on Emerging Technologies in NDT, Ioannina, Greece, 131-136.

El Masri, Y., \& Rakha, T. (2020). A scoping review of non-destructive testing (NDT) techniques in building performance diagnostic inspections. Construction and Building Materials, 265, 120542. https://doi.org/10.1016/j.conbuildmat.2020.120542

for preserving cultural heritage, Proceedings of the fifth conference on Emerging Technologies in NDT, Ioannina, Greece, 71-76.

Francesca Cau, Alessandra Fanni Augusto Montisci, Pietro Testoni, Mariangela Usai (2006); A signal processing tool for non-destructive testing of inaccessible pipes; Engineering Applications of Artificial Intelligence, 19(7), 753-760.

G. S. Park, P. W. Jang, Y. W. Rho (2001); Optimum Design of a Non Destructive Testing System to Maximize Magnetic Flux Leakage; Journal of Magnetics, 6(1), 31-35.

Gabriel Dan Taşcă, Gheorghe Amza; Research regarding ultrasonic examination of complex parts.

Gerd Dobmann, Iris Altpeter, Bernd Wolter (2008); Materials characterization a challenge in NDT for quality management; International Non-Destructive Testing Symposium and Exhibition, Istanbul Turkey.

Gholizadeh, S. (2016). A review of non-destructive testing methods of composite materials. Procedia Structural Integrity, 1, 50-57. https://doi.org/10.1016/j.prostr.2016.02.008

Giovanni M. Carlomagnoet, Carosena Meola (2002); Comparison between thermographic techniques for frescoes NDT, NDT \& E International, 35(8), 559-565.

H. A. Crostack, W. Reimers ( 2001); Evaluation of component integrity by non-destructive testing; International Journal of Materials and Product Technology, 3(2), 147 - 162.

Hay, T.R \& Rose, J.L. (2003); Fouling detection in the food industry using ultrasonic guided waves, Food-Control 14(7), 481-488.

Ignacio Garcia de Carellan, Phil Catton, Cem Selcuk \& Tat-Hean Gan (2011); Methods for detection and cleaning of fouling in pipelines, Proceedings of the fifth conference on Emerging Technologies in NDT, Ioannina, Greece, 231-236.

J. Skramlik, M. Novotny \& K. Suhajda (2011); Apparatus for measuring of liquid conductivity, Proceedings of the fifth conference on Emerging Technologies in NDT, Ioannina, Greece, 489-494.

Gupta, M., \& Khan, M. A. (2021). Advances in applications of non-destructive testing (NDT): a review. International Research Journal of Engineering, IT \& Scientific Research, 7(3), 76-86. https://doi.org/10.21744/irjeis.v7n3.1003 
J.S. Clausen, N. Zoidis \& A. Knudsen (2011); Onsite measurements of concrete structures using Impact-Echo and Impulse Response, Proceedings of the fifth conference on Emerging Technologies in NDT, Ioannina, Greece, $117-122$

Jacek Jarmulak, Eugene J.H. Kerckhoffs, Peter Paul van't Veen (2001); Case-based reasoning for interpretation of data from non destructive testing; Engineering Applications of Artificial Intelligence; 14(4), 401-417.

Javier García-Martín, Jaime Gómez-Gil and Ernesto Vázquez-Sánchez (2011); Non-Destructive Techniques Based on Eddy Current Testing, Sensors, 11(3), 2525-2565.

Jolly, M. R., Prabhakar, A., Sturzu, B., Hollstein, K., Singh, R., Thomas, S., ... \& Shaw, A. (2015). Review of nondestructive testing (NDT) techniques and their applicability to thick walled composites. Procedia CIRP, 38, 129136. https://doi.org/10.1016/j.procir.2015.07.043

K. Bollas, D. Papasalouros, D. Kourousis \& A. Anastasopoulos (2011); Acoustic emission monitoring of wheel sets on moving trains, Proceedings of the fifth conference on Emerging Technologies in NDT, Ioannina, Greece, 341 346.

Li Zhijun (2001); Non-Destructive Testing of Advanced Composites; Aerospace Materials \& Technology.

Lohr, K.R. \& Rose, J.L. (2003); Ultrasonic guided wave and acoustic impact methods for pilpe fouling detection, Journal-of-Food-Engineering 56(4), 315-324.

M. Ohtsu, T. Matsuo, S. Nozaki \& Y. Kawasaki (2011); AE monitoring of shrinkage process in concrete, Proceedings of the fifth conference on Emerging Technologies in NDT, Ioannina, Greece, 143-148.

M.D. Beard, M.J.S. Lowe (2003); Non-destructive testing of rock bolts using guided ultrasonic waves, International Journal of Rock Mechanics and Mining Sciences, 40(4), 527-536.

M.S. Kovačević, A. Mirčeta \& D. Marčić (2011); NDT and safety of crude oil storage tanks, Proceedings of the fifth conference on Emerging Technologies in NDT, Ioannina, Greece, 477-482.

Mc Clements, D.J. (1995); Advances in the application of ultrasound in food analysis and processing, Trends in Food Science and Technology, 6, 293-299.

N. Meyendorf, B. Frankenstein \& L. Schubert (2011); Structural health monitoring for aircraft, ground transportation vehicles, wind turbines and pipes_-prognosis, Proceedings of the fifth conference on Emerging Technologies in NDT, Ioannina, Greece, 15-22.

N. Tsopelas, D. Kourousis, I. Ladis, A. Anastasopoulos, D.J. Lekou \& F. Mouzakis (2011); Health monitoring of operating wind turbine blades with acoustic emission, Proceedings of the fifth conference on Emerging Technologies in NDT, Ioannina, Greece, 347-352.

P Cawley (2001); Non-destructive testing - current capabilities and future directions; Journal of Materials: Design and Applications; 215, 213-223.

P. Tschelisnig (2001); Acoustic emission testing (AET) an integral non-destructive testing method; International Journal of Materials and Product Technology, 3(3/4), 267 - 275.

Rainer Pohl , A Erhard, H.J Montag , H.-M Thomas, H Wüstenberg (2004); NDT techniques for railroad wheel and gauge corner inspection; NDT \& E International, 37(2), 89-94.

Rodrigo Benenson, Stephane Petti, Thierry Fraichard, Michel Parent (2008); Towards urban driverless vehicles; International Journal of Vehicle Autonomous Systems, 6(1/2), $4-23$.

Suprenant, B. \& Schuller, M. (1994); Non destructive evaluation \& testing of masonry structures, The Aberdeen Group, USA.

T. Kek \& J. Grum (2011); AE monitoring at laser cutting, Proceedings of the fifth conference on Emerging Technologies in NDT, Ioannina, Greece, 321-326.

Tsioulou, O., Lampropoulos, A., \& Paschalis, S. (2017). Combined non-destructive testing (NDT) method for the evaluation of the mechanical characteristics of ultra high performance fibre reinforced concrete (UHPFRC). Construction and Building Materials, 131, 66-77. https://doi.org/10.1016/j.conbuildmat.2016.11.068

Umesh Singh, Mohan Singh and M. K. Singh (2012); Analysis study on surface and sub surface imperfections through magnetic particle crack detection for nonlinear dynamic models of some mining components; Journal of Mechanical Engineering Research, 4(5), 185-191.

Withers, P.M. (1994); Ultrasonics for the detection of fouling. Food Technology International Europe 1994, 96-99 (Reprint 768). 